\title{
SASKATCHEWAN'S SMALLEST FLOWERING PLANTS
}

BRADLEY J. MUIR, 24-80 Hanbidge Crescent, Regina, Saskatchewan. S4R 6N2

By mid-summer in Saskatchewan thousands of slow moving creeks and still water bodies are covered with a thick green mat of vegetation. A close inspection reveals that this mat is composed of thousands of minute plants. These are the duckweeds of the cosmopolitan family Lemnaceae. The four genera with 28-30 species, inhabiting freshwater and rarely brackish water, represent the smallest flowering plants in the world. ${ }^{123}$

Three species are found in Saskatchewan. By far the most frequent and abundant is the Lesser Duckweed (Lemna minor L.). This, the smallest of the three, is the major component of the 'blooms' that form floating emerald carpets on prairie sloughs. Its close relative, the Ivy-leaved Duckweed (Lemna trisulca L.), forms a tangled lattice-work that is usually submersed and easily overlooked. While these members are generally distributed throughout the province, the third species is limited to the northern portion of Saskatchewan. The Larger Duckweed (Spirodela polyrhiza (L.) Schleiden) inhabits marsh and bog environments of the boreal forest.

\section{Morphology}

The most striking feature of the Lemnaceae is their simplicity. Both floral and vegetative reduction is drastic. The plants are not differentiated into leaf and stem. The individual plants are called 'fronds', however this term does not imply any relationship to the ferns. Most taxonomists believe that the portion nearest the rootlet was originally the stem (of axial origin) and the other portion originally the leaf (of foliar origin). ${ }^{2}$
The fronds range from roughly ovate or oblong to elongate or irregular. The largest fronds are those of the Ivyleaved Duckweed at about $1 \mathrm{~cm}$. The pale to deep green plants average only $2 \mathrm{~mm}$ in thickness, each being a few cells thick with large intracellular air spaces present.

The duckweeds are vascular plants, but here again structural reduction is evident. Since the plant is in contact with water over most of its surface nutrients can be absorbed through the epidermis as well as the rootlets. Translocation of nutrients and metabolites is subsequently simplified.

In the two floating species (Lesser Duckweed and Larger Duckweed) the upper epidermis is cuticularized (waxy) and not easily wetted. This and the presence of pendant rootlets keeps the plant upright and seldom if ever are they found upside down.

One to many rootlets may be present. In the Larger Duckweed each rootlet is composed of a single vascular strand and a root cap. Rootlets of the Lesser Duckweed have no vascular tissue but bear a large root cap. The Ivy-leaved Duckweed is not often found with welldeveloped rootlets. In the floating species rootlets originate from a furrow on the underside of the plant. Depending upon growing conditions they may reach up to $4 \mathrm{~cm}$ in length.

\section{Reproduction}

One re-adaptation of aquatic plants is reproduction by vegetative means. In the duckweeds this form is by far the most important. Flowers and fruit are scarce and rarely seen in most species. ${ }^{123} 4$ 
KEY TO THE DUCKWEEDS (LEMNACEAE) OF SASKATCHEWAN

1. a) Plants with several rootlets to a frond, reddish to purplish beneath. 4-15 dark nerves radiating from a central node, nearly oval. (Fig. 1)

Spirodela polyrhiza

1. b) Plants with one rootlet to a frond, fronds greenish on all surfaces, 1-5 obscure nerves.

Lemna

2. a) Fronds $2-6 \mathrm{~mm}$ long, roughly ovate, usually floating on surface. (Fig. 2) Lemna minor

2. b) Fronds $6-10 \mathrm{~mm}$ long, medium to long-stalked, remain attached forming zigzag chain. (Fig. 3)

Lemna trisulca

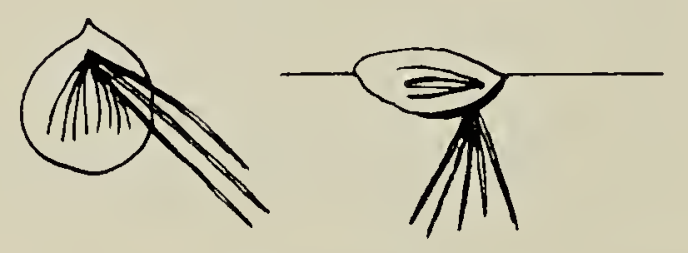

$(\mathbb{1 1})$

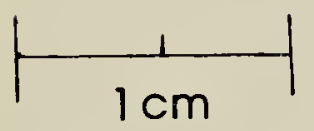

Figure 2
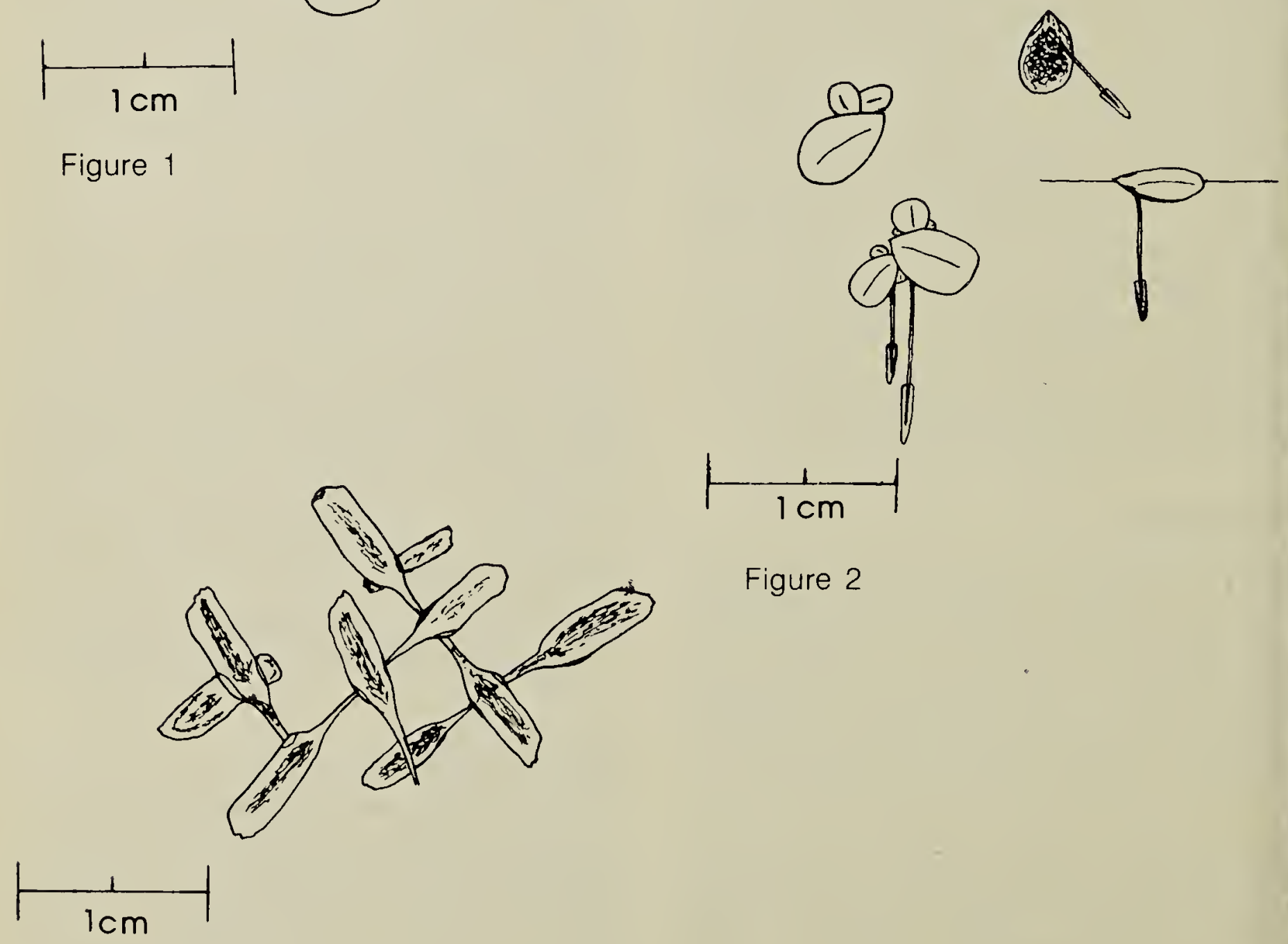

Figure 3 
Normally 'daughter' fronds bud from two small membranous pockets located near the basal margin of the parent frond. (Fig. 4) The rate of growth is primarily dependent on light intensity and duration. ${ }^{456}$ Under laboratory conditions frond number may double as frequently as every three or four days in the Lesser Duckweed. ${ }^{6}$ Growth in the other two species found in Saskatchewan is not as rapid under similar conditions.

In the Lesser and Larger Duckweeds the fronds become detached and small 'colonies' of 2 to 8 fronds result. The Ivyleaved Duckweed remains attached and colonies of 10 to 20 are not uncommon. The submerged character of this species permits budding and expansion of the zig-zag chain in three planes. The resulting networks are intricate lattices of medium to long-stalked fronds in different developmental stages.

As mentioned earlier the flowers of duckweeds are not often found. This is not only due to their rarity but also because of their size and inconspicuous colour. It literally resembles "the head of a pin" and may be overlooked or mistaken for lint or fungus.

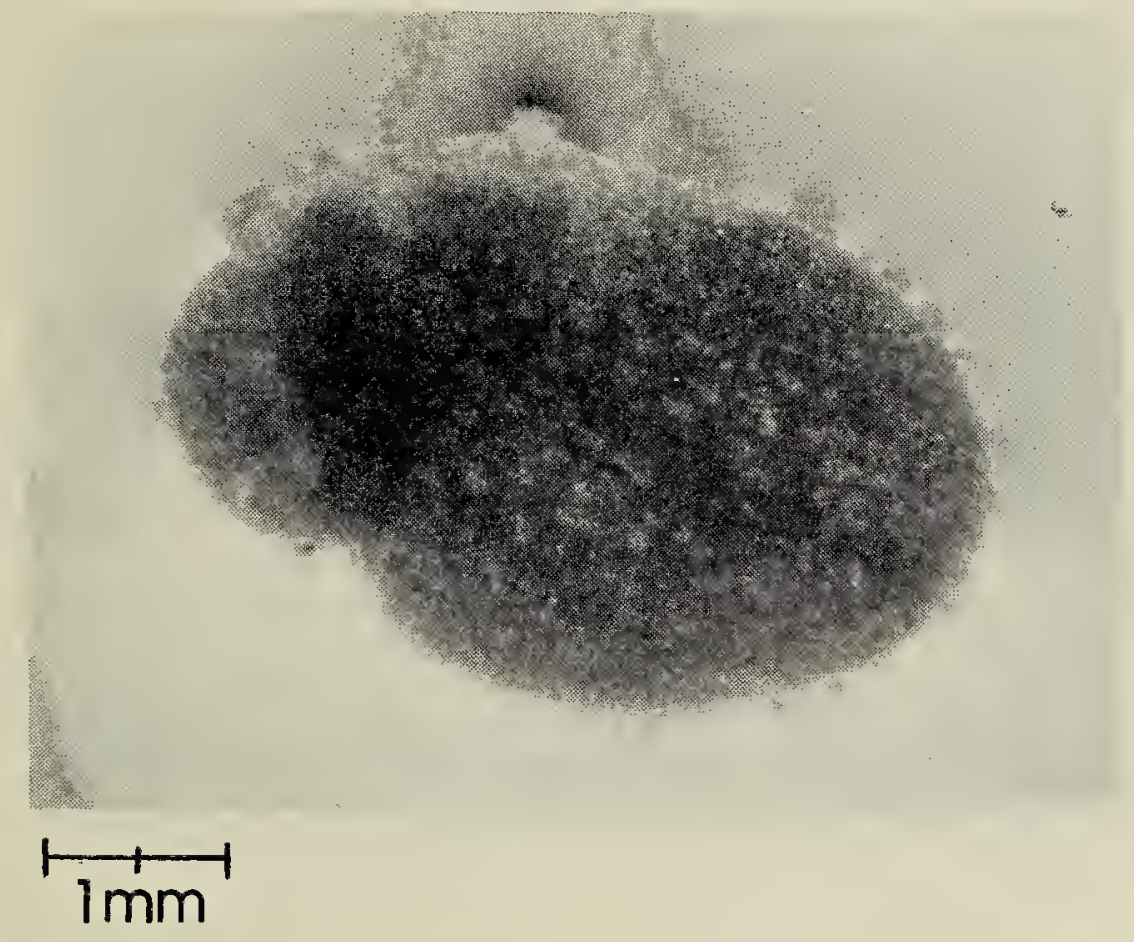

Figure 4
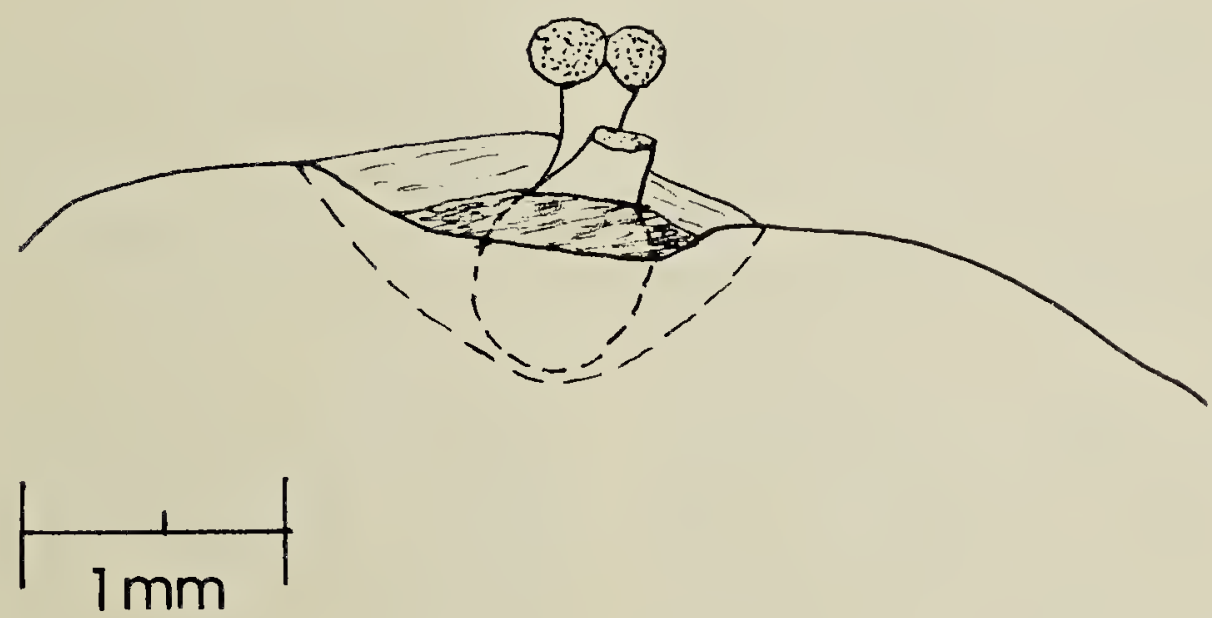

Figure 5 


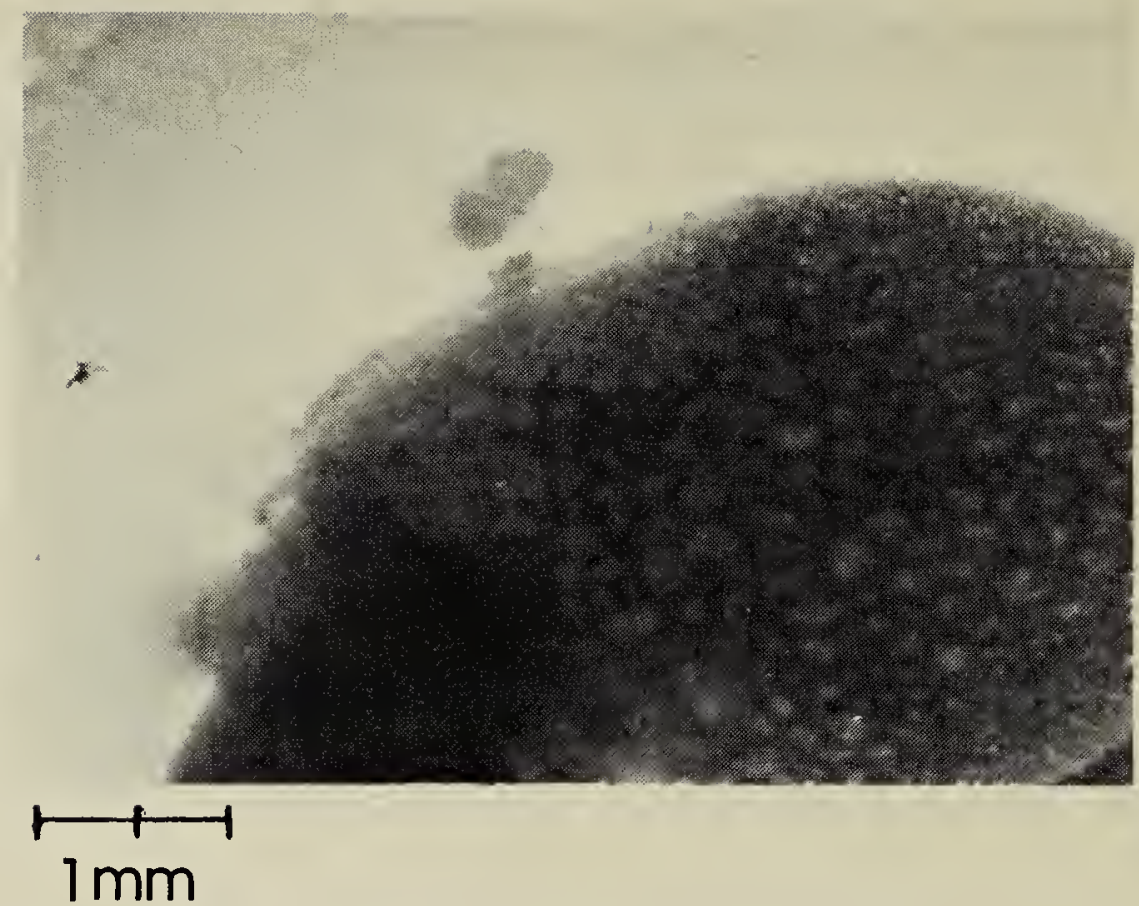

Figure 6

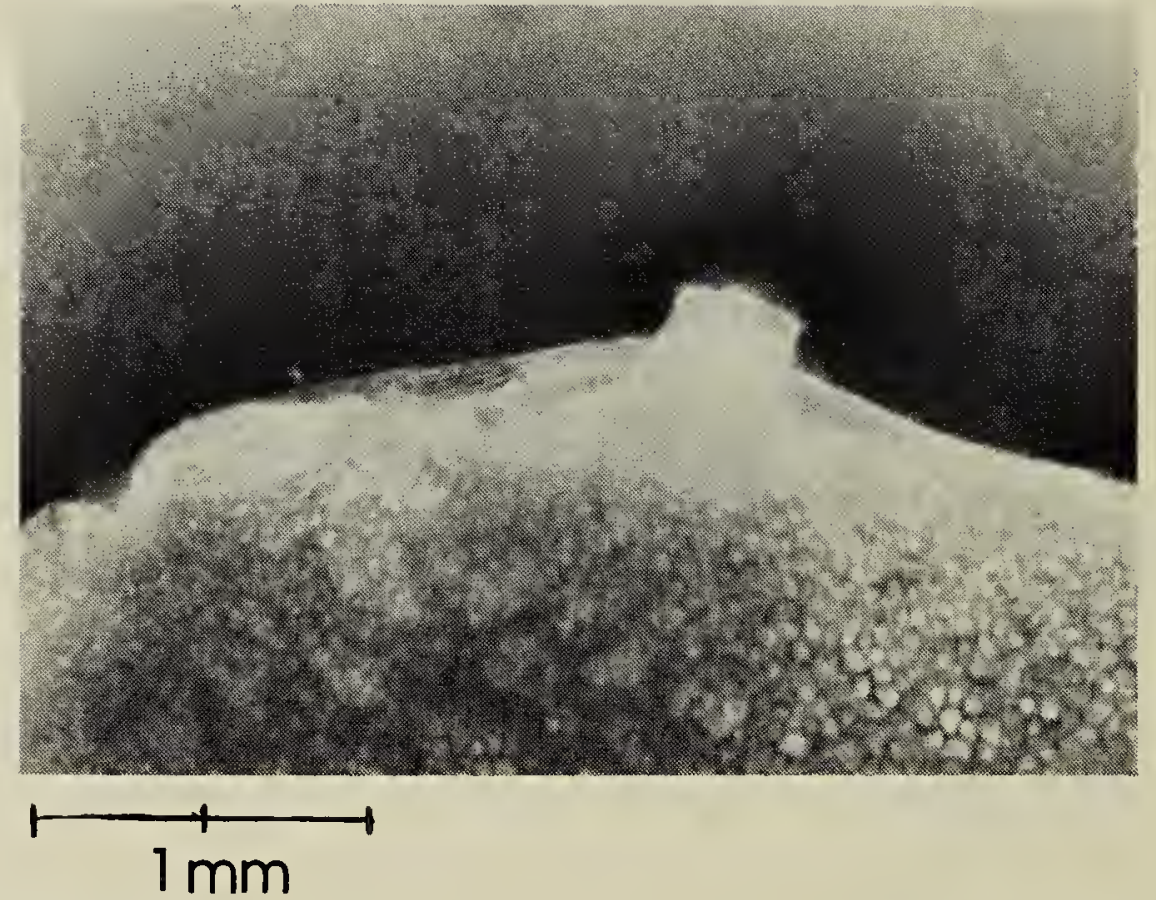

Figure 7

The inflorescence is extremely reduced with no petals or sepals. (Fig. 5) The male flowers bear one or two rigid stamens with a low output of pollen. ${ }^{2}$ (Fig. 6) The plants are monoecious and a typical female flower appears on the same plant as a male flower but the timing of their individual maturity is staggered to prevent self-pollination. The female flower consists of a single pistil with a flask-shaped ovary. (Figs. 5 and 7) The plants are probably pollinated by insects but not exclusively because wind and physical contact are also likely pollinators since the plants are highly gregarious. ${ }^{2}$
The individual plants survive only a single season with overwintering accomplished as seed or by means of a modified frond called a 'turion'. Little is known about the precise nature of these structures. In the Larger Duckweed they are darker in colour than the vegetative fronds and are somewhat kidneyshaped. ${ }^{5}$ In autumn the air spaces become packed with starch which makes the turions heavier than water and they sink.

\section{Ecology}

In nature the duckweeds are important primary producers. Besides 
affecting the dissolved oxygen regime they are consumed by vegetarian fish, crustaceans and insects. Waterfowl and other marsh birds eat the plants themselves but in addition the microenvironment created by the masses of duckweeds harbors many invertebrates, in various life cycle stages, on which these vertebrates thrive. ${ }^{7}$

Large mammals may ingest the fronds incidentally while feeding. Certain caddis flies (Order Trichoptera) use the fronds of the Ivy-leaved Duckweed in the construction of their larval cases.

The thick carpets of duckweeds on small water bodies may inhibit evaporation thus small ponds may persist longer into the summer supporting a variety of other species.

The cycling of heavy metals in aquatic ecosystems may be in part affected by the duckweeds. Studies have shown that Lemna minor can accumulate significant levels of boron and can grow in media with high concentrations of boron without exhibiting phytotoxic effects. ${ }^{6}{ }^{8}$

The plants sometimes become nuisances in reservoirs and dug-outs as they clog pumping and filtration systems. Massive population explosions may choke sluggish waterways. The duckweeds are not susceptible to copper sulfate treatment like the algae and neither are they toxic like the algae. ${ }^{9}$ Certain herbicides have been used effectively against dense blooms. Removal by raking is effective over small areas. ${ }^{9}$

In tropical countries certain species of Lemna along with other aquatic plants are collected and used as cattle fodder. No reports of this are known from Saskatchewan where other fodder is practically and economically more feasible. Lemna minor has a nutritional value reportedly similar to that of alfalfa. A danger exists in the possible use of the plants as feed in that toxic algae may contaminate the duckweed.

Duckweeds are eminently suitable for laboratory experiments. Scientists have used these diminutive monocots in mineral nutrition studies, interspecific competition studies, plant population biology, and have performed bioassays and toxicity tests with them. ${ }^{1011} 126813$

\section{Conclusion}

The duckweeds are a well adapted and extremely successful family of aquatic plants. Their role in Saskatchewan's aquatic ecosystems is undoubtedly substantial and one which in the future may be examined both in the laboratory and in the field. Knowledgeable and observant naturalists may make significant contributions to the study of the Lemnaceae by noting the occurrence of flowering and first appearance of plants in the wild each season. Hopefully the content of this article might serve as a starting point for this work.

\section{Acknowledgements}

Much of the impetus and information for this paper was the result of my work carried out in an undergraduate research class at the University of Regina. The study reported on the phytotoxic effects of boron using Lemna minor $L$. An offshoot of this work was the detection of flowering in laboratory populations. I wish to extend thanks to my supervisor, Dr. A. Walther.

FERNALD, M. L. 1950. Gray's Manual of Botany, 8th Ed. Amer. Book Co., N.Y.

${ }^{2}$ SCULTHORPE, C. D. 1967. The Biology of Aquatic Vascular Plants. E. Arnold Pub., London.

${ }^{3}$ HITCHCOCK, CRONQUIST, OWNBEY \& THOMPSON 1969. Vascular Plants of the Pacific Northwest Vol. I. University of Wash. Press. 
${ }^{4}$ HILLMAN, W. S. 1959. Experimental control of flowering in Lemna I. General methods. Photoperiodism in L. perpusilla 6746. Amer. Jour. Bot. 46: 466473.

${ }^{5}$ JACOBS, D. L. 1947. An ecological life history of Spirodela polyrhiza with emphasis on the turion phase. Ecol. Mono. 17: 438-469.

${ }^{6}$ MUIR, B. J. 1981. Unpublished. A feasibility study using Lemna minor $L$. in a bioassay for boron phytotoxicity.

${ }^{7}$ FASSETT, N. C. 1966. Manual of Aquatic Plants. Univ. Wisc. Press, Madison.

${ }^{8}$ GLANDON, R. P. and C. D. MCNAB 1978. The uptake of boron by Lemna minor. Aqua. Bot. 4: 53-64.
${ }^{9}$ GUIDE TO AQUATIC NUISANCE CONTROL. Environment Saskatchewan pub. 1978.

${ }^{10}$ STEINBERG, R. O. 1941. Use of Lemna for nutrition studies on green plants. Jour. Agr. Res. 62: 423-430.

"HARPER, J. L. 1961. Approaches to the study of plant competition. In F. L. Milthorpe Ed. Mechanisms in Biological Competition. Symp. Soc. Exp. Bot. 15: 1-39.

${ }^{12}$ HARPER, J. L. 1978. Population Biology of Plants. Acad. Press, London.

${ }^{13}$ LOCKHART, W. L. and A. P. BLOUW 1979. Phytotoxicity tests using the duckweed, Lemna minor. Can. Pub. Fish. Aq. Sci., Gov't. Canada.

\section{COTTONWOOD: A RARE TREE NEAR THE PAS, MANITOBA}

\section{WALTER KRIVDA, Box 864 , The Pas, Manitoba. R9A 1 K8}

For a quarter of a century I have been looking for the Cottonwood (Populus deltoides) on my various collecting trips.

I was aware of records further west in Saskatchewan and also of my own record from Riding Mountain National Park - on the highway between the North Gate of the Park and Dauphin. There is also an old report from Vermillion Park in Dauphin and The Flora of Canada identifies this report as the furthest north location in Manitoba for this species. ${ }^{1}$

The first local record of the Cottonwood was in the 1960's when a single tree with many dozens of suckers forming was found. This tree was found on the edge of a farm field, in the then, just opened up Pasquia settlement area about 170 miles north of Dauphin. This clone has since enlarged and is deeply entrenched, is not being disturbed and the crop is planted around it.
The second local record for the Cottonwood was made when plant collections were made on the Carrot River Road between The Pas and the Saskatchewan border, a distance of about 35 miles. Here also a single tree was found along the highway. This is a solitary tree which is not cloning.

This entire local area was heavily flooded in 1948. The water was so deep that only the cross bars on the tops of the telephone poles were visible. If Populus deltoides cannot stand a whole summer's drowning, it may well be that these two trees arrived as seeds after the water subsided, which would make them just short 35 years of age. It would be interesting to take increment borings to discover the actual ages of the trees.

The third and final local record, for the present, of the Cottonwood consists of several trees on the shore of Readers Lake at Wachie Bay a short walk from 